\title{
Classroom Learning Motivators: Breaking ESL Chinese University Students' Passivity in Class Discussion
}

\section{Leah Li Echiverri}

College of Liberal Arts, Wenzhou Kean Univeristy, China.

\begin{abstract}
Chinese university students enrolled in overseas coursework and English as Medium of Instruction courses domestically have a reputation for classroom passivity as recognized internationally. Thus, the case study was employed to explore Wenzhou Kean University (WKU) students' 'willingness to communicate' based on motivation and attitude toward the classroom learning milieu. Purposive and convenience sampling techniques were used in the semistructured interview of 75 informants during the focus group discussion. Thematic content analysis method was used to analyze qualitative data collected. Grounded theory was used for the generation of theories. Findings showed that ESL Chinese university students are motivated because of knowledge acquisition and English spoken ability improvement when they engage in class discussion. A relaxing classroom climate, instructor's personality and professional competence in designing the learning experiences contribute in shaping favorable learning attitudes necessary for active student participation in class discussion. Most WKU students intend to pursue graduate studies abroad and considers English speaking ability important in their future and career goals. This belief persistently motivates them to engage in class discussion. Besides, thinking skills development, self-confidence enhancement, leadership skills, team working and adaptability to new environment development heighten the importance of class discussion.
\end{abstract}

Keywords: Class discussion, language learning motivators, career goal motivators, classroom learning motivators, content language and integrated learning. 


\section{Introduction}

In this era of global competitiveness and internationalism, English, as an international language, is increasingly being promoted in China. To keep abreast with this trend, the teaching of English is a prioritized reform of the Chinese government in which English is already incorporated in the curriculum as a compulsory course for college students (Zhou \& Zhao, 2016). According to Wei and $\mathrm{Su}$ (2012) English is the most popular foreign language studied by foreign-language learners in China but a low degree of frequency in the use of 'English' was reported among Chinese English language learners.

Ample studies on the 'Passive Asian Learner' that is globally recognized have been reported. Key themes to explain the passivity of Asian learners revolve around the following: Confucian Education that teaches students to be passive (Tran, 2013); Willingness to Communicate and Anxiety (Fu \& Wang \& Wang, 2012); Unfamiliarity with the discussionbased pedagogy (Jackson \& Chen, 2017); Neglect of speaking fluency strand in EFL education in China and the Exam oriented learning promotes linguistically unprepared Chinese learners (Yang, 2014).

The literature review fairly contradicts the findings of Echiverri and Lane (2019) study that reported ESL Chinese University students enrolled at Wenzhou Kean University (WKU) responded positively to interactive activities similar to the type common to ESL classes. Emulating ESL methods specifically Task-Based Interactive Approach (TBIA) to support student spoken interaction in a Research Methodology (RM) class strongly correlated to student satisfaction and perceived learning. An important highlight of the research was that students came to RM class, a Content and Language Integrated Learning (CLIL) course, with a tacit English learning expectation in addition to the learning of the specified course content. The researchers concluded that motivation and perceived learning were served by the language learning agenda, and that the language learning agenda was served by contentoriented in class speaking tasks.

In WKU, the English Immersion Program is used where all classes are taught in English. Consistent to the 'Passive Asian learner' phenomenon, a widespread challenge encountered by majority of WKU instructors relates to ESL students' passivity when it comes to class discussion. According to Cortazzi and Jin (as cited in Tran, 1996) Asian students' passivity is described and criticized as being quiet, "reluctant to participate in classroom activities, unwilling to give responses, avoid asking questions and over-dependent on the teacher".

The literature on the passiveness of Asian students abounds already. Instead, the researcher focused its investigation on the factors that motivate ESL university students to be active in class discussion (speaking class task) and its importance to their future and career goals. Besides, there is still a paucity of research on promoting English in CLIL courses. 
Motivation plays an essential part in language learning (Zhou \& Zhao, 2016). According to Dornyei (as cited in Zhou \& Zhao, 1994), "Motivation is responsible for why people decided to do something, how long they are willing to sustain the activity, and how hard they are going to pursue it." Zhou and Zhao further cited the integrative and instrumental classification of motivation. "Learners with 'integrative motivation' want to learn a language in order to communicate with people of the target society and culture. In contrast, learners with 'instrumental motivation' want to learn a language because it will be useful for certain goals, such as passing a test, getting a job, improving status, obtaining certificates and so on."

Gardner (2006) described 'integrative motivation’ a combination of three components made up of the individual's desire to learn the other language plus willingness to communicate with other members of the other language plus the favorable attitude toward the language learning situation (pp.11-12). According to Heckhausen and Kuhl (as cited in Gardner, 1985) two types of motivational constructs are emphasized in the study namely: the motivation to learn (and acquire) a second language and the classroom learning motivation. Gardner described these aspects in the learning situation that will have influences on the individual's classroom learning motivation namely as follows: "the teacher, the class atmosphere, the course content, materials and facilities, as well as personal characteristics of the student (such as studiousness, etc.,)."

The researcher assumed that students enrolled are integratively motivated to learn the English language in order to communicate with the target society and culture particularly so when WKU students intend to pursue graduate studies abroad. Researcher was interested in how can WKU instructors design the classroom learning milieu that fosters students' favorable learning attitudes to elicit active participation. Thus, the study aimed to explore the motivational factors in the classroom learning milieu that aids to encourage ESL university students to actively participate in class discussion in both English language courses and CLIL courses. Secondly, the study investigated the learners' attitudes on the importance of English speaking ability to their future and career goals.

\section{Methodology}

This exploratory-case study design conducted at WKU used the qualitative mode of inquiry to be able to collect in-depth information and extent of variation of responses from participants of the study. Purposive and convenience non-random sampling technique were used in the selection of informants. Upon reaching saturation point, the sample size was composed of 75 cases, representing $3 \%$ of the 2018 academic year student population. Crosssectional representation of the sample composed of nearly $50 \%$ freshmen students while the remaining $50 \%$ were a mixture of sophomore, junior, and senior students. 
Ten groups of six cases and three groups of five cases participated in the focus group discussion (FGD). The informants were asked to discussed the following questions: a. What classes motivate you? Why did you feel motivated? Was discussion part of that lesson? b. What are your future and career goal/plans? How important is English speaking ability (class discussion) to your plans? Flexibility and spontaneity throughout the semi-structured interview process by applying follow-up questions and asking for or giving explanation of terms were applied for clarity and shared understanding.

Thematic content analysis method, both semantic and latent analysis, was used to analyze collected descriptive data although outliers were noted as well. Grounded theory was used in theory generation.

\section{Findings and Discussion}

WKU students defined discussion as a "face to face and see each other talk with professors and the whole class." Interestingly, participants consider these class activities as types of discussion like small group discussion, class interviews, debate, role-playing and presentations. Whole class discussion was portrayed as "in circle formation." Small group discussion was often at the top of students' minds; many would unhesitatingly offer answers such as "Oral English class, because we get to have conversations."

\subsection{Language Learning Motivators (LLMs)}

3.1.1 During the FGD, discussion was for the majority a component of motivation. When further asked what motivates them to actively participate in discussion, unsurprisingly the students' responses consistently supported Gardner's language learning motivation with these statements "learning new ideas" and "when professors teach a lot, I learn a lot" thematically labelled as knowledge enrichment.

3.1.2 Similar statements such as "I practice English in presentations and discussion", "Discussion improves my ability to communicate with others"; "discussion gives more 'freedom' to practice in English and express my "voice",; and "everyone expresses his/her thoughts and learn to talk with others." were thematically labelled as English spoken language improvement.

\subsection{Classroom Learning Motivators (CLMs)}

Students' responses on the motivational factors in the classroom learning milieu that foster favorable attitudes were remarkably consistent to Gardner's aspects of classroom learning motivation detailed in themes as follows:

3.2.1. Relaxing Classroom climate. Most students described a 'relaxing environment' motivates them to actively participate in class discussion. This summarizes the statements 
described as "being with a classmate who is also a friend"; "there is familiarity' between and among themselves", and "three to four students engaged in group discussion." Linking statements to make them feel "relax" were "Good relationship with classmates", "team working" and "when professors interact with them." Some WKU students cited that "group rotation" to expand their circle of friends" was good.

3.2.2. Teacher's personality. This factor represents the teachers' qualities like "humorous, makes jokes, kind, helpful, easy going, and patient made them say "I felt good and enjoyed that class". Professors that are enthusiastic and they 'can talk and interact with' were often cited too. A surprising common pattern mentioned frequently was professors who 'talk slowly and clearly' for students to understand better' was likable contrary to some professors who talked "fast" and "use strange words".

3.2.3. Professional Competence in Designing the Learning Experiences. This factor encapsulates the professional competence of the instructor in designing the events of instruction that respondents find motivating and were thematically labelled as follows:

3.2.3.1 Learning objectives to represent statements of "professors give clear instructions what we need to do in class and after class."; and when "aims or objectives of the class are clear."

3.2.3.2 Curriculum Content to represent 'interesting topics' furthered explained by students when "topics have relevance in their study life and daily life like food, sports and news"; and "topics that are not too hard and appropriate to their understanding." Few students mentioned that the "professors' style of using the current news to connect with the lesson catch their attention to actively listen."

3.2.3.4 Instructional strategies to represent 'active learning' portrayed by these statements: "give students more chances to speak and express ideas"; "let students speak; not the professor does all the talking". It was surprising to hear students' fondness to engage in active learning events such as "brainstorming, drama, role playing, debate, small group discussion and presentations." These activities made them "think" and "practice English" all the time. Moreover, students expressed liking to "professor gives examples for clarity and making use of stories for clearer understanding"; "professors start the class with a review and ends the class with a summary" and technology integration such as "use of videos, WeChat and kahoot".

3.2.3.5 Assessment to represent statements that "professors give feedback of our presentations and affirmation for good work" and "rewards for the best group and giving of bonus points". 


\subsection{Career Goal Motivators (CGMs)}

During the FGD regarding the perceived importance of 'class discussion' in relation to learners' future and career goals, many had clearly unambiguous answers. Worth noting is the respondents' intention to return to China to share their 'knowledge and learning' after completing a master's degree abroad, although a minority of them said they would want to look for a job thereafter. Very few responded to look for a job after their WKU graduation.

Most WKU students presumed that graduate studies and future career will require English speaking ability in instances like admission to graduate school, job recruitment and promotions, and value to employer. Hence, respondents stated the perceived benefits of the importance of class discussion to career and future goals thematically labelled as follows:

3.3.1 Thinking skills development encapsulates students' comparable pronouncements of "discussion is helpful for mind development"; "discussion improves my thinking abilities"; "discussion makes me think and stimulates my critical thinking"; "discussion opens my mind to be creative." Striking statements were "I am able to listen to different opinions and learn from the ideas of others"; "Other ideas inspire my thoughts and broaden my horizon" thereby subsequently, "makes me rethink of my ideas to make changes as to what is right."

3.3.2 Self-confidence enhancement portrays associated statements of "I used to be shy but presentations make me brave"; "I practice to deliver talk in public" and "Discussion makes me outgoing."

3.3.3 Team working, leadership and adaptability development encapsulates related statements of "I learn to work as a team"; "I learn to respect the ideas and opinions of other people" and "discussions make me learn to work with others and adapt to new people." A number though stated that "discussions can develop my leadership".

\subsection{Conceptual Framework and Implications}

Overall learning from the perspective of the student is highly influenced by three main factors - namely, career goal motivators (CGMs), language learning motivators (LLMs) and classroom learning motivators (CLMs) see Figure 1. Career goal motivators are determined by the student themselves as they decide what career they want to pursue. However, since this is a long term goal, the determination of the student is a manifestation of the depth of the student's desire for such a career.

Language learning motivators may push the student to further get acquainted with a language which he or she believes will significantly contribute to his/her success in his/her chosen career. Hence, he/she may want to get into exchange programs which will allow him/her to be immersed in both the culture and language of his/her choice. 
Classroom learning motivators then becomes critical in the further reinforcement of the career goal motivators and the language learning motivators. In the classroom, if a positive learning environment is created, it can further enhance the career goal motivation as well as the language learning motivation of the student. Therefore, the role of the classroom learning motivators, and hence the role of the instructor, becomes crucial in the making or breaking of the first two motivators (CGMs and LLMs).

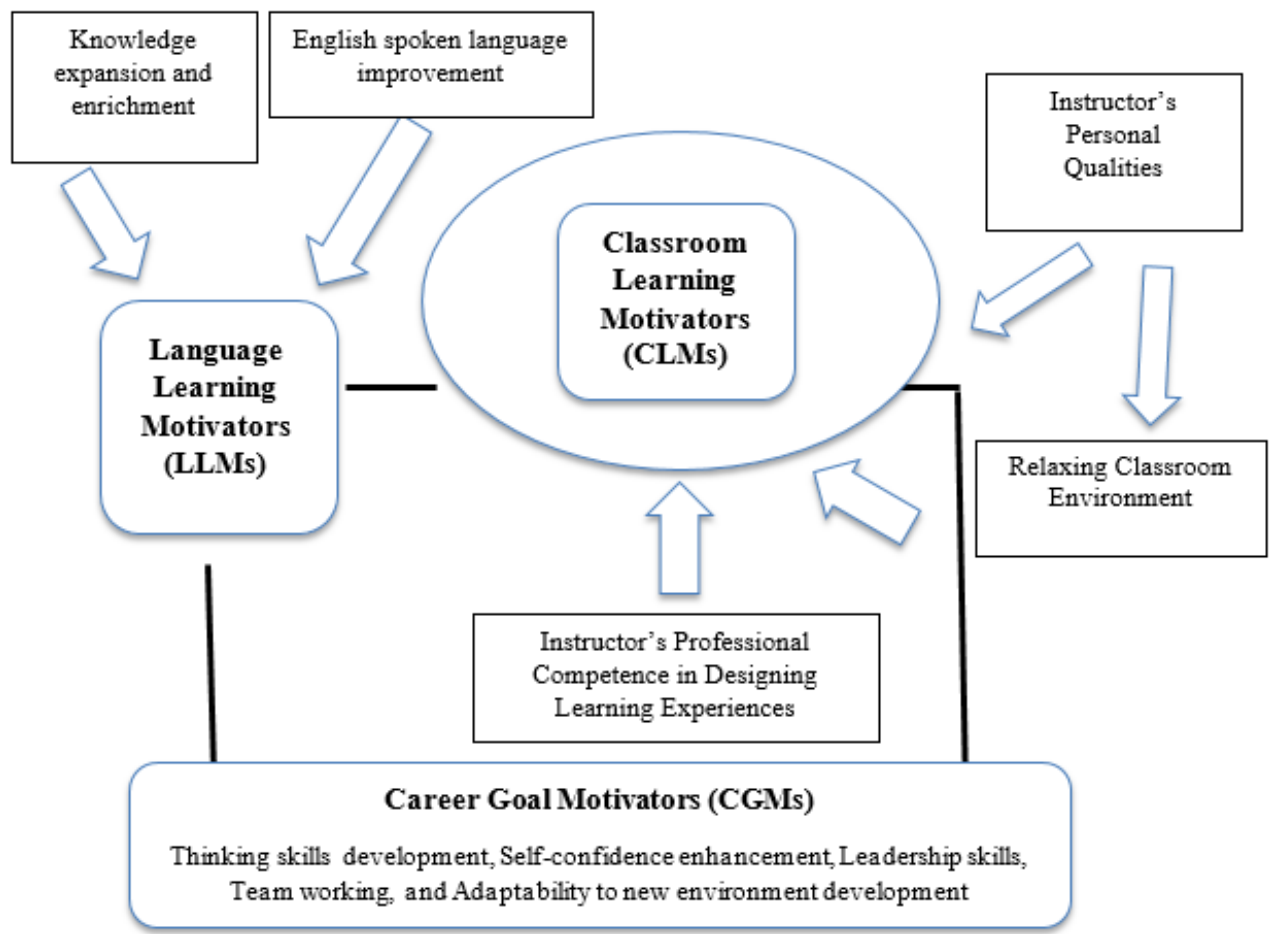

Figure.1. Class Discussion Learning Motivators

The CLMs that shape a favorable attitude to ESL university students towards active participation in class discussion are a relaxing classroom climate, personal qualities of instructors, and instructor's professional competence in designing the learning experiences.

Classroom instructors are advised to create a relaxing classroom climate whereby students feel comfortable and relaxed. Such conditions require familiarity with classmates, formation of groups in small sizes, and entailing professors to mill around and interact with students during small group discussion. Students' favored personal qualities of instructors such as being humorous, friendly, enthusiastic towards teaching, kind, helpful, does not talk too fast, interacts with students, and paying attention to them. Hence, instructors are encouraged to consciously manifest these personal qualities that will contribute in creating a comfortable and relaxed mood classroom climate. 
The following events of instruction are suggested to advance Instructor's Professional Competence in designing learning experiences: 1. presentation of objectives, 2 . building on students' prior knowledge using 'active learning' as springboard to knowledge expansion on course topics 3. application of Task-based interactive approach (TBIA) in processing technical knowledge transfer and technology integration, 4. relating content to real life situations, 5. giving of timely feedback and 6. giving of awards or rewards for best individual/group outputs.

\section{Acknowledgments}

Dr. Leah Li Echiverri would like to express appreciation to Professor Keith Lane, Wenzhou Kean University for his collaboration on the research reported.

\section{References}

Echiverri, L. L., \& Lane, T.K. (2019). Influence of Learning Attitudes and Task-Based Interactive on ESL Student Satisfaction and Perceived Learning Outcomes in a Content and Language Integrated Learning (CLIL) University Course in China. Teachers' Professional Development in Global Contexts: Insights from Teacher Education. (pp.140-159). Leiden, Netherlands: BRILL Sense doi:10.1163/9789004405363_008

Fu, L., Wang, X., \& Wang, Y. (2012). The research on willingness to communicate in Chinese students' EFL study. Journal of Language Teaching and Research; 3, (1), 112 117.

Gardner, R.C (2006). Motivation and Second Language Acquisition ${ }^{1}$. Paper presented at the Seminario Sobre Plurilinguismo: Las Aportaciones Del Centro Europeo de Lenguas Modernas de Graz, on December 15, 2006, Universidad de Alcalá, Spain.

Jackson, J., \& Chen, X. (2017). Discussion-based pedagogy through the eyes of Chinese international exchange students. Pedagogies: An International Journal. 13 (4), 289-307. doi: 10.1080/1554480X.2017.1411263

Sun, Y. (2008). Motivation to speak: Perception and attitude of non-English major students in Taiwan, (Doctoral dissertation). Available from ProQuest Dissertations (No.3342202)

Tran, T. T. (2013). Is the learning approach of students from the confucian heritage culture problematic? Educational Research for Policy and Practice, 12(1), 57-65. doi: 10.1007/s10671-012-9131-3

Wei, R., \& Su, J. (2012) The statistics of English in China. English Today 111, 28 (3), 1014. doi:10.1017/S0266078412000235

Yang, Y I, J. (2014). Is speaking fluency strand necessary for the college students to develop in the EFL class? Theory and Practice in Language Studies, 4(2), 225-231. doi:10.4304/tpls.4.2.225-231

Zhou, Y., \& Zhao, J. (2016). Three primary tasks of the first college english class in china. Theory and Practice in Language Studies, 6(11), 2186-2190. doi: $10.17507 /$ tpls.0611.16 